Neurosurg Focus 23 (3):E8, 2007

\title{
Treatment options for Cushing disease after unsuccessful transsphenoidal surgery
}

\author{
James K. LiU, M.D., ${ }^{1,2}$ Maria FleseriU, M.D., ${ }^{2}$ Johnny B. Delashaw JR., M.D., ${ }^{2}$ \\ Ivan S. Ciric, M.D., ${ }^{1}$ and William T. Couldwell, M.D., Ph.D. ${ }^{3}$ \\ ${ }^{1}$ Department of Neurological Surgery, Northwestern University Feinberg School of Medicine, \\ Evanston Northwestern Healthcare, Evanston, Illinois; ${ }^{2}$ Department of Neurological Surgery, \\ Oregon Health and Science University, OHSU Pituitary Unit, Portland, Oregon; and \\ ${ }^{3}$ Department of Neurosurgery, University of Utah School of Medicine, Salt Lake City, Utah
}

\begin{abstract}
$\checkmark$ Cushing disease is considered an aggressive pituitary endocrinopathy because of the devastating effects from untreated hypercortisolemia. Although they are histologically benign, these adrenocorticotropic hormone (ACTH)-secreting pituitary tumors are associated with significant morbidity and premature death. Currently, transsphenoidal surgery is the primary treatment of Cushing disease associated with an ACTH-secreting pituitary tumor, resulting in remission rates ranging from about 50 to $90 \%$. Some patients, however, will not achieve sustained remission after transsphenoidal surgery and can exhibit persistent or recurrent Cushing disease that requires multimodal treatment to achieve remission. In these patients, options for treatment include repeat transsphenoidal resection, radiation therapy (including conventional fractionated radiation therapy and stereotactic radiosurgery), and medical therapy. Despite undergoing multiple treatment modalities, some patients may ultimately require bilateral adrenalectomy for definitive treatment to eliminate hypercortisolemia associated with Cushing disease. In this article, the authors review the treatment options for patients who have persistent or recurrent Cushing disease after unsuccessful transsphenoidal surgery. The indications, current results reported in the literature, and complications of each treatment modality are discussed.
\end{abstract} (DOI: 10.3171/FOC-07/09/E8)

\section{KEY WORDS • adrenalectomy - Cushing disease • pituitary adenoma • stereotactic radiosurgery - transsphenoidal surgery}

$\mathrm{C}$ USHING disease, which is induced by a functional ACTH-producing adenoma of the anterior pituitary gland, is the most common cause of ACTH-dependent Cushing syndrome. The treatment of Cushing disease remains challenging for neurosurgeons and endocrinologists. Transsphenoidal surgery is currently the treatment of choice in patients who harbor ACTH-secreting pituitary tumors associated with Cushing disease. This surgery provides the best option for rapid biochemical remission with excellent long-term results. Remission rates after transsphenoidal resection performed by experienced surgeons have ranged from approximately 70 to $90 \% .3 ., 15,17,26,37,38,42$. ${ }^{47,54}$ Long-term follow-up with biochemical testing is necessary to detect tumor recurrence because remission rates decline with longer follow-up periods. ${ }^{14,16}$ Although many patients achieve complete remission, these tumors are difficult to cure surgically, and some patients may exhibit persistent or recurrent hypersecretion of ACTH and hypercortisolism resulting in increased morbidity and death related

Abbreviations used in this paper: $\mathrm{ACTH}=$ adrenocorticotropic hormone; $\mathrm{CRH}=$ corticotropin-releasing hormone; $\mathrm{GABA}=\gamma$ aminobutyric acid; GI = gastrointestinal; $\mathrm{MR}=$ magnetic resonance; SRS $=$ stereotactic radiosurgery. to their malignant endocrinopathy. Unfortunately, the results of endocrinological analyses after transsphenoidal surgery vary in the literature because different definitions of a biochemical cure are given in the various studies.

If biochemical evidence of Cushing disease persists or recurs after an initial transsphenoidal surgery, the surgeon should be familiar with the treatment options available to offer the patient, including repeat transsphenoidal surgery, radiation therapy, medical therapy, and bilateral adrenalectomy. A multimodal approach using a combination of these treatments may be an appropriate strategy in some patients to achieve the best outcome. For optimal results, a multidisciplinary team approach should be coordinated at a specialized center. In this paper, we provide an overview of the management options available after unsuccessful transsphenoidal surgery and review the current outcome data for each option based on results reported in the literature.

\section{Repeat Transsphenoidal Surgery}

As indicated earlier, transsphenoidal surgical removal of ACTH-producing pituitary adenomas is currently recommended as the first-line treatment for Cushing disease. The reported rates of remission are variable because of the wide 
variety of remission criteria from each publication. In a recent review, Utz and colleagues ${ }^{62}$ reported a possible remission rate of 70 to $90 \%$ of cases; however, if patients are followed up for many years, the overall remission rate is expected to decline. For example, Atkinson and associates ${ }^{5}$ reported an overall remission rate of 56\% at 9.6 years after transsphenoidal surgery.

If biochemical evidence establishes that Cushing disease is not controlled and hypercortisolemia persists or recurs, repeat transsphenoidal surgery is a reasonable option, with remission rates as high as $70 \% .^{27,40,52}$ The timing between the first and second surgery is variable and can range from several days in the immediate postoperative period to 6 to 12 weeks. If obvious hypercortisolemia persists $(\geq 6$ $\mu \mathrm{g} / \mathrm{dl}$ ) on endocrine testing at postoperative Day 3, a repeat transsphenoidal surgery should be considered in the immediate postoperative period, particularly if a pituitary tumor was detected initially on preoperative MR imaging, if a tumor was found intraoperatively, and if an ACTH-positive staining tumor was detected on histopathological analysis. If no adenoma is detected or findings on preoperative MR imaging are equivocal (which is not infrequent), a positive inferior petrosal sinus sampling study, which has a sensitivity and specificity approaching 100\% for Cushing disease, ${ }^{51}$ provides the surgeon with additional evidence that $\mathrm{ACTH}$ production is from a pituitary source when considering reexploration. ${ }^{40}$ This strategy of early repeat transsphenoidal surgery offers a chance to achieve rapid remission of hypercortisolism before the formation of scar tissue, enabling the surgeon to recall anatomical details from the earlier operation. ${ }^{52}$

Few investigators address the results of repeat transsphenoidal surgery in the immediate postoperative period. ${ }^{27,52}$ Ram and coworkers ${ }^{52}$ reported 17 patients who underwent repeat transsphenoidal surgery within 7 to 46 days after the initial resection. Twelve $(71 \%)$ of the 17 patients attained remission after the second surgery; however, only $9(53 \%)$ sustained remission at 84 months. During the second operation, adenomectomy with or without partial hypophysectomy was performed if a tumor was found; hemihypophysectomy was performed if a tumor was absent at the second surgery but was present either intraoperatively or histologically in the specimen from the first operation; and complete hypophysectomy was performed if a tumor was absent at both surgeries.

Friedman et al. ${ }^{27}$ also reported a similar remission rate of $73 \%$ in 33 patients who underwent an unsuccessful initial transsphenoidal surgery; however, hypercortisolism reoccurred in $13 \%$ at 10 to 47 months postoperatively. A recent study included 44 patients with Cushing disease who underwent second transsphenoidal surgery. ${ }^{8}$ Initial remission in this study was attained in $57 \%$ with further relapse in $25 \%$. Locatelli and associates ${ }^{40}$ used more stringent criteria for a biochemical cure and defined surgical failure as a serum cortisol level that did not fall below $2 \mu \mathrm{g} / \mathrm{dl}$ at 72 hours after surgery. Twelve patients underwent immediate reoperation for persistent Cushing disease based on these criteria, and remission was achieved in 8 patients $(67 \%)$. All 12 patients underwent hypophysectomy (10 total hypophysectomies, 2 subtotal hypophysectomies) rather than selective adenomectomy, and all patients had some degree of hypopituitarism, with the majority (67\%) having panhypopituitarism.
No clear predictors of remission have been described in the published literature for the second transsphenoidal surgery. Some authors have reported that the presence of an adenoma on initial MR imaging or during the initial surgery is a positive predictor, whereas the absence of an adenoma during the second surgery is a negative predictor. In the report by Ram and colleagues ${ }^{52}$ surgical or histological confirmation of an ACTH-positive adenoma that was incompletely resected during the initial operation was the most significant predictor of a successful second operation in terms of remission and avoiding hypopituitarism. Friedman et al. ${ }^{27}$ recommended repeat transsphenoidal exploration of the pituitary gland with treatment limited to selective adenomectomy. If an adenoma is identified during surgery, the chance of remission of Cushing disease is high and the risk of hypopituitarism is low; however, if no adenoma can be found and partial or complete hypophysectomy is performed, remission of hypercortisolism is less likely and the risk of hypopituitarism is greater than $50 \%$.

Repeat transsphenoidal surgery is a relatively safe and effective treatment option with few postoperative complications. The risk of hypopituitarism is higher after repeat transsphenoidal surgery (ranging from 41 to $50 \%$ ) than after the first surgery, but is still lower than that associated with radiation therapy. ${ }^{27,52}$ The degree of hypopituitarism is somewhat related to the degree of resection (partial or total hypophysectomy) attempted at the second surgery. The most frequent pituitary deficiency in surgically induced remission of Cushing disease after gonadotrophic deficiencies is growth hormone deficiency, which occurs in 13 to $65 \%$ of cases. $^{30}$ Pituitary macroadenomas that secrete ACTH are rare (4-10\% of all ACTH pituitary tumors); ${ }^{33}$ thus, the published data concerning remission are scarce. As expected, the remission rate of patients with these macroadenomas is dismal; in one study, it was reported to be just $30 \%$, with further cortisol normalization/cure in about half the patients after combined second surgery, radiation therapy, and medical treatment. ${ }^{12}$

If a patient has a recurrent or residual tumor in the sellar region with extension into the cavernous sinus, one strategy is to remove the sellar portion at the second surgery and follow that procedure with planned radiosurgery to the cavernous sinus. This option can decrease tumor volume for subsequent radiosurgery. Because of the risk of hypopituitarism from radiation exposure to the normal pituitary gland, pituitary transposition (hypophysopexy) can be performed at surgery in cases of planned radiosurgical treatment of residual pituitary adenoma within the cavernous sinus to reduce the radiation dose to the normal pituitary gland. ${ }^{22,39}$ During the sellar exploration for tumor resection, the pituitary gland is transposed away from the region of the cavernous sinus, and a fat and fascia graft is interposed between the normal pituitary gland and the residual tumor in the cavernous sinus. This graft increases the distance between the normal pituitary gland and the residual cavernous sinus tumor, which may reduce radiation exposure to the normal pituitary gland.

\section{Radiation Therapy}

Pituitary irradiation has been used for several decades as an adjunctive therapy in treating pituitary tumors, particularly for residual or recurrent tumors after resection. The 
goals of this radiation therapy are to control pituitary hypersecretion associated with minimal hypopituitarism, prevent future tumor growth, and possibly diminish tumor size. Radiation therapy may serve as a primary treatment in some patients who cannot medically tolerate resection or who have tumors in a surgically inaccessible location, such as the cavernous sinus. ${ }^{55}$ Conventional fractionated radiation therapy has historically been the primary radiation treatment in Cushing disease, but in the last decade or so, SRS has emerged as the primary modality for radiation therapy for pituitary tumors. There is a delay from the time radiation therapy is initiated until the time it takes effect on hypercortisolemia; therefore, medical therapy is initiated and continued for some time until the radiation therapy takes effect during the lag period.

The remission rates after conventional fractionated radiation therapy have been reported to range from 56 to $84 \%$ in patients with Cushing disease. ${ }^{25,46}$ Minniti and colleagues ${ }^{46}$ treated 40 patients with persistent or recurrent Cushing disease after transsphenoidal surgery with conventional fractionated radiation therapy (45-50 Gy in 25-28 fractions) with a median follow-up of 9 years; the 10-year survival rate in this study was $95 \%$. The percentage of patients with normalization of plasma cortisol was $73 \%$ at 3 years, $78 \%$ at 5 years, and $84 \%$ at 10 years. The average time to remission was 2 years. Hypopituitarism was present in 62 and $76 \%$ of patients at 5 and 10 years after radiation therapy, respectively. Estrada and associates ${ }^{25}$ reported similar results, with a remission rate of $83 \%$ in 30 patients after a median follow-up of 42 months (range 18-114 months). The time to remission in this study ranged from 6 to 60 months after radiation therapy, with the majority of remissions occurring in the first 2 years. There were no relapses in the patients who achieved remission. Hypopituitarism was present in $57 \%$ of the patients, and no other adverse effects were seen.

Although conventional radiation therapy has demonstrated effectiveness in controlling ACTH secretion, its related complications have limited its usefulness. ${ }^{55}$ The incidence of hypopituitarism after fractionated radiation therapy to the pituitary varies between 50 and $100 \%$ several years after treatment. ${ }^{7,67}$ Additional complications associated with conventional radiation therapy to the sella include radiation necrosis, cerebral vasculopathy, damage to surrounding sellar and parasellar structures (including visual damage), and the development of radiation-induced neoplasms. ${ }^{11,21,28,56}$ There is often a delay of several years between treatment and effective control of tumor growth and hormone production. Failures of conventional fractionated radiotherapy have been attributed, in part, to an inability to deliver adequate doses accurately to a small tumor volume while sparing the surrounding structures. ${ }^{31,55}$ These concerns have resulted in increased use of SRS for refractory Cushing disease. In a large review of 35 studies in which SRS was used to treat pituitary tumors, Sheehan et al.55 concluded that SRS appeared to lead to faster normalization of hormone levels than fractionated radiotherapy with apparently lower risk of hypopituitarism, visual deterioration, and radiation-induced neoplasms.

As reported by Sheehan and coworkers, ${ }^{55}$ the rates of remission for Cushing disease after SRS have ranged from 17 to $83 \%$ in series with more than 10 patients and a median follow-up of 2 years. The variability in reported remission rates is due in part to differing criteria for defining an endocrinological cure by different authors. At most centers, endocrinological remission is generally defined as a normal urinary free cortisol level in conjunction with resolution of clinical signs or a series of normal postoperative serum cortisol levels obtained throughout the day. ${ }^{55}$

In one of the largest SRS series to date, Jagannathan and coworkers $^{31}$ evaluated 90 patients with Cushing disease who underwent Gamma knife SRS at a mean dose of 23 Gy to the tumor margin with a mean follow-up of 45 months (range 12-132 months). All but one patient had unsuccessful prior transsphenoidal surgery. One patient who had a cavernous sinus tumor underwent SRS as the primary treatment without resection. Biochemical remission (defined as normalization of 24-hour urinary free cortisol levels) was achieved in 49 patients (54\%), with a mean time to remission of 13 months. Ten patients $(20 \%)$ who achieved remission after SRS experienced relapse, with a mean time to recurrence of 27 months. This rate of relapse after initial remission emphasizes the importance of long-term, and perhaps lifelong, follow-up. Sixty-nine percent of patients had a decrease in tumor size, and $22 \%$ suffered a new hormone deficit. The most common newly developed deficit was hypothyroidism, followed by growth hormone deficiency. Five patients experienced ophthalmoplegia from a third, fourth, or sixth cranial nerve deficit, and of these, four had additional visual deficits. Of these five patients, two had previous conventional fractionated radiation therapy and four had previous SRS. One patient who had previous conventional radiation therapy and two SRS treatments developed blindness in both eyes. These results suggest that repeated radiation treatments increase the risk of optic neuropathy and cranial nerve deficit.

Although SRS appears to be a promising modality for adjunctive therapy, longer-term follow-up is necessary to determine the durability of initial remission as well as the true percentage of delayed complications from SRS, such as hypopituitarism, visual and cranial nerve neuropathy, and radiation-induced tumors. It is also important to keep in mind that if the tumor is in close proximity to the optic nerves, fractionated radiation therapy, rather than SRS, may offer a more suitable dose plan that is tolerated by the optic nerves.

\section{Medical Therapy}

Medical therapy for Cushing disease is rarely initiated as a first-line treatment, but rather serves an adjunctive role after an unsuccessful attempt at transsphenoidal resection while other treatment options are being considered or initiated. For example, medical therapy can serve as a bridging treatment until remission from radiosurgery takes effect. In some patients who cannot safely tolerate surgery, medical therapy can be considered. If medication is the only therapy, however, discontinuation of treatment will invariably result in recurrence unless another form of treatment, such as radiosurgery, is administered.$^{50}$ Most studies regarding medical therapy for treatment of hypercortisolism were performed in patients with adrenocortical carcinoma and bilateral adrenal hyperplasia, but some reports note the use of these therapies in Cushing disease. Overall, medical treatment may be useful in up to one third of patients. ${ }^{45}$

There are three potential mechanisms of action for med- 
ical therapy: 1) inhibition of steroidogenesis; 2) modulation of ACTH release; and 3) receptor blockade with glucocorticoid antagonists (Table 1).

\section{Inhibition of Steroidogenesis}

Inhibitors of steroidogenesis decrease cortisol production by direct inhibition at one or more enzymatic steps, which can result in partial or complete inhibition of cortisol synthesis. The most commonly used agents of this inhibitor class are ketoconazole, mitotane, trilostane, aminoglutethimide, and metyrapone. The effectiveness of each drug as a sole therapy is controversial. Combinations of these drugs may have additive or synergistic effects, allowing smaller doses of each drug with fewer side effects. One disadvantage of the use of these agents is the need to increase the dose to maintain normal cortisol levels because the setpoint for cortisol negative feedback is higher in ACTH-secreting pituitary tumors than in the normal pituitary gland. $.^{50} \mathrm{Be}-$ cause the risk of adrenal insufficiency is high, frequent monitoring of plasma or urine cortisol is necessary. Another widely used approach is total blockade of the adrenal gland with glucocorticoid replacement, but the balance between normal cortisol levels and exogenous hypercortisolism is hard to maintain.

Ketoconazole is an imidazole derivative that inhibits cytochrome P450 enzymes including 17,20-lyase, $11 \beta$-hydroxylase, and $17 \alpha$-hydroxylase and side-chain cleavage. The typical dosage of ketoconazole ranges from 400 to $1200 \mathrm{mg}$ per day. Ketoconazole has been shown to decrease urinary cortisol levels effectively in patients with Cushing disease. ${ }^{57} \mathrm{~A}$ metaanalysis of 82 patients with presumed Cushing disease showed that monotherapy with ketoconazole effectively reduced plasma cortisol levels in $70 \%{ }^{24}$ Some reports have shown that ketoconazole prevents the expected compensatory increase in ACTH secretion in patients with Cushing disease, suggesting that it may impair ACTH release. ${ }^{41}$ Other investigators have shown that basal ACTH levels were increased after treatment, suggesting that the drug may not suppress corticotrope tumors..$^{10}$ In general, the major effect of ketoconazole is on the adrenal cortex. Side effects from this drug include GI distress and gynecomastia, occurring in fewer than $15 \%$ of patients. ${ }^{19,50}$ Elevated levels of hepatic transaminases are also common, thus requiring periodic monitoring of liver function tests. Because of its favorable adverse effect profile, twice-daily dosing, and relative effectiveness as a single-agent therapy, ketoconazole has emerged as the agent of choice for the medical treatment of Cushing disease.

Mitotane inhibits side-chain cleavage, 11- and 18-hydroxylase, and $3 \beta$-hydroxysteroid dehydrogenase. Its main use is in treatment of adrenocortical carcinoma, but it appears to have some suppressive effects on ACTH as well. Because of its adrenolytic effects, mitotane has been effective in the management of Cushing disease, with remission achieved in $83 \%$ of patients at a dose of 8 to $12 \mathrm{~g}$ per day. ${ }^{43}$ Sixty percent of patients relapsed, however, suggesting the need for additional adjuvant therapy. A lower incidence of relapse (30\%) was observed in the patients who received radiation therapy in addition to mitotane. Because mitotane increases glucocorticoid metabolism and serum binding proteins, replacement therapy requirements are adjusted to three- to sevenfold higher than the average dose. Adverse
TABLE 1

Medical therapy for Cushing disease

drugs that inhibit steroidogenesis
ketoconazole
mitotane
metyrapone
trilostane
aminoglutethimide
etomidate
drugs that modulate ACTH release
dopamine agonists
bromocriptine
cabergoline
somatostatin agonists
octreotide
GABA agonists
valproic acid
serotonin antagonists
cyproheptadine
ketanserin
ritanserin
cortisol-receptor antagonists
mifepristone (RU-486)

effects of mitotane use include GI discomfort, neurological symptoms (such as abnormal gait, dizziness, vertigo, confusion, and anomia), gynecomastia, rash, hypercholesterolemia, and hepatotoxicity.

Metyrapone, an inhibitor of $11 \beta$-hydroxylase, may be used as monotherapy or in combination with radiation therapy for Cushing disease. ${ }^{50}$ In one study of 53 patients with Cushing disease, normalized urine cortisol levels were achieved in $75 \%$, using an average dose of $2250 \mathrm{mg}$ of metyrapone per day (range 750-6000 mg) over a short-term course (1-16 weeks). ${ }^{64}$ Metyrapone was administered long term (median 27 months, range 3-140 months) in 24 patients who had been treated with pituitary irradiation, with adequate control of hypercortisolemia achieved in 20 patients (83\%). ${ }^{64}$ Adverse effects include hypertension, acne, hirsutism, hypokalemia, edema, nausea, and dizziness.

Trilostane, a $3 \beta$-hydroxysteroid-dehydrogenase inhibitor, is a relatively weak inhibitor of steroidogenesis. It is not potent enough to block cortisol biosynthesis in patients with hypercortisolism, and thus the remission rates of patients receiving trilostane have been poor and somewhat variable. $^{23,24}$ Side effects include GI discomfort, diarrhea, and paresthesias.

Aminoglutethimide inhibits the side-chain cleavage of cortisol biosynthesis (cholesterol to pregnenolone). As a monotherapy, aminoglutethimide is not very useful; instead, it is most effective when given in combination with other drugs, such as metyrapone..$^{50}$ The dose is usually 250 mg administered two to three times daily. Side effects include GI symptoms, headache, dizziness, depression, and blurred vision.

Etomidate is an imidazole derivative that inhibits cholesterol side-chain cleavage and $11 \beta$-hydroxylase. It has a strong inhibitory effect and has been shown to reduce plasma cortisol levels in patients with Cushing disease. ${ }^{53}$ Etomidate is the only agent that can be given to patients intravenously. 


\section{Modulation of ACTH Release}

Because ACTH hypersecretion remains under hypothalamic control in Cushing disease, neuromodulatory agents, such as neurotransmitter agonists and antagonists acting on the hypothalamic-pituitary axis, can influence ACTH or $\mathrm{CRH}$ release. Neuromodulatory agents have been used in patients with Cushing disease after unsuccessful transsphenoidal surgery or radiation therapy with mixed results. No randomized trials have been described, and most of the positive results are due to acute administration, leaving the real therapeutic potential unknown.

The most frequently used ACTH release modulators are somatostatin analogs (octreotide), dopamine agonists (bromocriptine), serotonin antagonists (cyproheptadine, ritanserin), and GABA agonists (sodium valproate). Their efficacy is variable between patients, and the exact mechanism of lowering ACTH is not completely understood. None of these agents has demonstrated consistent clinical efficacy.

Octreotide, a somatostatin analog, is generally ineffective in lowering ACTH levels in Cushing disease. Octreotide was shown to inhibit CRH-stimulated ACTH secretion in vitro but not in vivo. This discrepancy was thought to be related to downregulation of somatostatin receptors by circulating cortisol in the presence of hypercortisolemia. ${ }^{59} \mathrm{On}$ the other hand, octreotide suppresses ACTH release in patients with Nelson syndrome. Combined treatment with octreotide and ketoconazole appeared to have an additive effect in normalizing urinary cortisol levels in three of four patients with severe ACTH-dependent hypercortisolism. ${ }^{65}$

More recently, a novel multiligand somatostatin analog, SOM230, has been demonstrated to inhibit ACTH release in human corticotrope cells in vitro by interacting with somatostatin receptor Type 5.6 Preliminary in vivo results suggest that SOM230 could be a promising drug in medical therapy for patients with Cushing disease; however, a longer follow-up is necessary to evaluate its therapeutic efficacy. ${ }^{2}$

Bromocriptine is a potent dopamine receptor agonist. The exact mechanism of action on ACTH modulation is not known; however, some investigators have suggested dopaminergic modulation of $\mathrm{ACTH}$ via $\mathrm{CRH}$ release, as well as direct suppression of ACTH. Approximately 40\% of patients had normalized urine or plasma cortisol levels after chronic bromocriptine treatment. ${ }^{45}$ Unfortunately, the ACTH response to a single dose of bromocriptine does not predict which patients respond to long-term therapy, and thus, higher doses may be needed to achieve a response. ${ }^{44}$ Bromocriptine reduced plasma ACTH levels in 12 patients postadrenalectomy with elevated ACTH levels in the absence of a pituitary macroadenoma. Yet there was no significant change when bromocriptine was combined with cyproheptadine. ${ }^{66}$ Long-term treatment with cabergoline (0.5 mg twice a week) resulted in a complete remission of Nelson syndrome, including normalization of ACTH levels and resolution of a pituitary macroadenoma. ${ }^{13}$

Cyproheptadine, a serotonin antagonist, was reported to normalize plasma ACTH and cortisol levels in patients with Cushing disease with a remission rate ranging from 30 to $50 \% .{ }^{36}$ Hypercortisolism recurred in some patients, however, despite continued use. The use of cyproheptadine has not been consistently favorable; ${ }^{1}$ side effects include somnolence and hyperphagia resulting in weight gain.
Sodium valproate increases endogenous GABA by inhibiting GABA-aminotransferase. This inhibition potentiates the effect of GABA and may inhibit CRH and hence ACTH release. Results have been variable in studies of the administration of sodium valproate to decrease ACTH levels in patients with Cushing disease. In the most recent study of 19 patients, sodium valproate was not useful either as alternative or adjunctive therapy to surgery. ${ }^{20}$

\section{Cortisol Receptor Antagonists}

Mifepristone (RU-486) is a steroid that binds competitively to glucocorticoid, androgen, and progestin receptors and inhibits the action of the endogenous ligands. ${ }^{50}$ Its has been mostly used in ectopic Cushing syndrome. Mifepristone suppresses the peripheral features of chronic hypercortisolism in nonpituitary-dependent Cushing syndromes. In Cushing disease, administration of mifepristone immediately induces a strong and long-lasting elevation of cortisol, reflecting corticotrope disinhibition. In one case, mifepristone was used in a patient with Cushing disease who underwent an unsuccessful combination of surgery, radiation treatment, and medical therapy. The treatment (up to $25 \mathrm{mg} / \mathrm{kg} /$ day of mifepristone) was very effective over an 18-month period, with normalization of all biochemical glucocorticoid-sensitive measurements. The patient developed severe hypokalemia believed to be related to excessive cortisol activation of the mineralocorticoid receptor, which responded to treatment with spironolactone. ${ }^{18}$

\section{Bilateral Adrenalectomy}

Bilateral adrenalectomy is a safe, effective, and definitive treatment for patients with refractory Cushing disease who have undergone multiple treatments unsuccessfully or when immediate reversal of hypercortisolemia is needed. Recently, this operation has been performed via a minimally invasive laparoscopic approach rather than by a traditional open approach because the minimally invasive approach results in fewer complications and a shorter inpatient hospital stay. A recent series of 12 patients with Cushing disease who had not attained remission using previous treatments (such as transsphenoidal surgery, radiotherapy, and medical therapy) showed that laparoscopic adrenalectomy was successful in resolving several signs and symptoms such as proximal myopathy, hirsutism, emotional lability, and weight loss. ${ }^{63}$ There was also an improvement in glucose tolerance and blood pressure control in all of these patients.

Patients undergoing bilateral adrenalectomy will require lifelong mineralocorticoid and glucocorticoid replacement, but their overall quality of life is improved when compared with their health preoperatively. ${ }^{29,61}$ One major concern after adrenalectomy is the development of Nelson syndrome in patients with ACTH-secreting pituitary adenomas. Nelson syndrome is characterized by elevated serum ACTH levels, hyperpigmentation, and progressively enlarging pituitary tumors that are often invasive and, in rare cases, may develop into pituitary carcinomas..$^{35,48,49}$ This incidence has been reported to be between 8 and $38 \%$ in some series, with corticotroph tumor progression as high as $40 \%$ over 20 years. ${ }^{4}$ Kemink and colleagues ${ }^{34}$ found that a predictive factor for developing Nelson syndrome was 
undergoing bilateral adrenalectomy at an earlier age. The incidence of Nelson syndrome after the treatment of Cushing disease is higher in children than in adults. ${ }^{60}$ Use of prophylactic pituitary radiation therapy to reduce the risk of developing Nelson syndrome is still debatable: some investigators have shown good results, ${ }^{32}$ whereas others have shown no significant difference. ${ }^{58}$

\section{Conclusions}

Cushing disease remains a challenging condition to treat, particularly if the disease persists or recurs after initial transsphenoidal surgery. The surgeon should be prepared to offer secondary interventions, including repeat transsphenoidal surgery, radiation therapy, medical therapy, or bilateral adrenalectomy. Some patients may need a combination of these treatments to attain remission. Long-term followup of patients to monitor the relapse of cortisol elevation is necessary. These patients are best cared for by a multidisciplinary neuroendocrine team at a specialized center comprised of neurosurgeons, endocrinologists, radiation oncologists, neuroophthalmologists, otolaryngologists, and general surgeons.

\section{Acknowledgments}

Drs. Liu and Fleseriu contributed equally to this paper. The authors thank Kristin Kraus for her editorial assistance.

\section{References}

1. Ambrosi B, Gaggini M, Secchi F, Faglia G: Lack of effect of antiserotoninergic and/or dopaminergic treatment in patients with pituitary-dependent Cushing's syndrome. Horm Metab Res 11: 318-319, 1979

2. Arnaldi G, Polenta B, Cardinaletti M, Boscaro M: Potential indications for somatostatin analogs in Cushing's syndrome. J Endocrinol Invest 28 (11 Suppl International): 106-110, 2005

3. Arnott RD, Pestell RG, McKelvie PA, Henderson JK, McNeill PM, Alford FP: A critical evaluation of transsphenoidal pituitary surgery in the treatment of Cushing's disease: prediction of outcome. Acta Endocrinol (Copenh) 123:423-430, 1990

4. Assié G, Bahurel H, Coste J, Silvera S, Kujas M, Dugué MA, et al: Corticotroph tumor progression after adrenalectomy in Cushing's disease: a reappraisal of Nelson's Syndrome. J Clin Endocrinol Metab 92:172-179, 2007

5. Atkinson AB, Kennedy A, Wiggam MI, McCance DR, Sheridan $\mathrm{B}$ : Long-term remission rates after pituitary surgery for Cushing's disease: the need for long-term surveillance. Clin Endocrinol (Oxf) 63:549-559, 2005

6. Batista DL, Zhang X, Gejman R, Ansell PJ, Zhou Y, Johnson SA, et al: The effects of SOM230 on cell proliferation and adrenocorticotropin secretion in human corticotroph pituitary adenomas. J Clin Endocrinol Metab 91:4482-4488, 2006

7. Becker G, Kocher M, Kortmann RD, Paulsen F, Jeremic B, Müller $\mathrm{RP}$, et al: Radiation therapy in the multimodal treatment approach of pituitary adenoma. Strahlenther Onkol 178:173-186, 2002

8. Benveniste RJ, King WA, Walsh J, Lee JS, Delman BN, Post KD: Repeated transsphenoidal surgery to treat recurrent or residual pituitary adenoma. J Neurosurg 102:1004-1012, 2005

9. Boggan JE, Tyrrell JB, Wilson CB: Transsphenoidal microsurgical management of Cushing's disease. Report of 100 cases. J Neurosurg 59:195-200, 1983

10. Boscaro M, Sonino N, Rampazzo A, Menegus AM, Mantero F: ACTH response to corticotropin releasing hormone in Cushing's disease before and after ketoconazole: in vivo and in vitro studies. Horm Metab Res Suppl 16:60-62, 1987

11. Brada M, Ford D, Ashley S, Bliss JM, Crowley S, Mason M, et al: Risk of second brain tumor after conservative surgery and radiotherapy for pituitary adenoma. BMJ 304:1343-1346, 1992

12. Cannavo S, Almoto B, Dall'Asta C, Corsello S, Lovicu RM, De Menis E, et al: Long-term results of treatment in patients with ACTH-secreting pituitary macroadenomas. Eur J Endocrinol 149:195-200, 2003

13. Casulari LA, Naves LA, Mello PA, Pereira Neto A, Papadia C: Nelson's syndrome: complete remission with cabergoline but not with bromocriptine or cyproheptadine treatment. Horm Res 62: 300-305, 2004

14. Chandler WF, Schteingart DE: Controversies in the management of Cushing's disease. Clin Neurosurg 33:553-562, 1986

15. Chandler WF, Schteingart DE, Lloyd RV, McKeever PE, IbarraPerez G: Surgical treatment of Cushing's disease. J Neurosurg 66:204-212, 1987

16. Chee GH, Mathias DB, James RA, Kendall-Taylor P: Transsphenoidal pituitary surgery in Cushing's disease: can we predict outcome? Clin Endocrinol (Oxf) 54:617-626, 2001

17. Chen JC, Amar AP, Choi S, Singer P, Couldwell WT, Weiss MH: Transsphenoidal microsurgical treatment of Cushing disease: postoperative assessment of surgical efficacy by application of an overnight low-dose dexamethasone suppression test. J Neurosurg 98:967-973, 2003

18. Chu JW, Matthias DF, Belanoff J, Schatzberg A, Hoffman AR, Feldman D: Successful long-term treatment of refractory Cushing's disease with high-dose mifepristone (RU 486). J Clin Endocrinol Metab 86:3568-3573, 2001

19. Colao A, Di Sarno A, Marzullo P, Di Somma C, Cerbone G, Landi ML, et al: New medical approaches in pituitary adenomas. Horm Res 53 (3 Suppl):76-87, 2000

20. Colao A, Pivonello R, Tripodi FS, Orio F Jr, Ferone D, Cerbone $\mathrm{G}$, et al: Failure of long-term therapy with sodium valproate in Cushing's disease. J Endocrinol Invest 20:387-392, 1997

21. Constine LS, Woolf PD, Cann D, Mick G, McCormick K, Raubertas RF, et al: Hypothalamic-pituitary dysfunction after radiation for brain tumors. N Engl J Med 328:87-94, 1993

22. Couldwell WT, Rosenow JM, Rovit RL, Benzil DL: Hypophysopexy technique for radiosurgical treatment of cavernous sinus pituitary adenoma. Pituitary 5:169-173, 2002

23. Dewis P, Anderson DC, Bu'lock DE, Earnshaw R, Kelly WF: Experience with trilostane in the treatment of Cushing's syndrome. Clin Endocrinol (Oxf) 18:533-540, 1983

24. Engelhardt D, Weber MM: Therapy of Cushing's syndrome with steroid biosynthesis inhibitors. J Steroid Biochem Mol Biol 49:261-267, 1994

25. Estrada J, Boronat M, Mielgo M, Magallón R, Millan I, Díez S, et al: The long-term outcome of pituitary irradiation after unsuccessful transsphenoidal surgery in Cushing's disease. N Engl J Med 336:172-177, 1997

26. Fahlbusch R, Buchfelder M, Muller OA: Transsphenoidal surgery for Cushing's disease. J R Soc Med 79:262-269, 1986

27. Friedman RB, Oldfield EH, Nieman LK, Chrousos GP, Doppman JL, Cutler GB Jr, et al: Repeat transsphenoidal surgery for Cushing's disease. J Neurosurg 71:520-527, 1989

28. Grattan-Smith PJ, Morris JG, Langlands AO: Delayed radiation necrosis of the central nervous system in patients irradiated for pituitary tumors. J Neurol Neurosurg Psychiatry 55:949-955, 1992

29. Hawn MT, Cook D, Deveney C, Sheppard BC: Quality of life after laparoscopic bilateral adrenalectomy for Cushing's disease. Surgery 132: 1064-1069, 2002

30. Hughes NR, Lissett CA, Shalet SM: Growth hormone status following treatment for Cushing's syndrome. Clin Endocrinol (Oxf) 51:61-66, 1999

31. Jagannathan J, Sheehan J, Pouratian N, Laws E, Steiner L, Vance 
M: Gamma Knife surgery for Cushing's disease. J Neurosurg 106:980-987, 2007

32. Jenkins PJ, Trainer PJ, Plowman PN, Shand WS, Grossman AB, Wass JA, et al: The long-term outcome after adrenalectomy and prophylactic pituitary radiotherapy in adrenocorticotropin-dependent Cushing's syndrome. J Clin Endocrinol Metab 80: $165-171,1995$

33. Katznelson L, Bogan JS, Trob JR, Schoenfeld DA, Hedley-Whyte ET, Hsu DW, et al: Biochemical assessment of Cushing's disease in patients with corticotroph macroadenomas. J Clin Endocrinol Metab 83:1619-1623, 1998

34. Kemink L, Pieters G, Hermus A, Smals A, Kloppenborg P: Patient's age is a simple predictive factor for the development of Nelson's syndrome after total adrenalectomy for Cushing's disease. J Clin Endocrinol Metab 79:887-889, 1994

35. Kemink SA, Wesseling P, Pieters GF, Verhofstad AA, Hermus AR, Smals AG: Progression of a Nelson's adenoma to pituitary carcinoma; a case report and review of the literature. J Endocrinol Invest 22:70-75, 1999

36. Krieger DT: Physiopathology of Cushing's disease. Endocr Rev 4:22-43, 1983

37. Laws ER, Vance ML, Thapar K: Pituitary surgery for the management of acromegaly. Horm Res 53 (3 Suppl):71-75, 2000

38. Laws ER Jr, Fode NC, Redmond MJ: Transsphenoidal surgery following unsuccessful prior therapy. An assessment of benefits and risks in 158 patients. J Neurosurg 63:823-829, 1985

39. Liu JK, Schmidt MH, MacDonald JD, Jensen RL, Couldwell WT: Hypophysial transposition (hypophysopexy) for radiosurgical treatment of pituitary tumors involving the cavernous sinus. Technical note. Neurosurg Focus 14(5):E11, 2003

40. Locatelli M, Vance ML, Laws ER: Clinical review: the strategy of immediate reoperation for transsphenoidal surgery for Cushing's disease. J Clin Endocrinol Metab 90:5478-5482, 2005

41. Loli P, Berselli ME, Tagliaferri M: Use of ketoconazole in the treatment of Cushing's syndrome. J Clin Endocrinol Metab 63: 1365-1371, 1986

42. Ludecke DK: Transnasal microsurgery of Cushing's disease 1990. Overview including personal experiences with 256 patients. Pathol Res Pract 187:608-612, 1991

43. Luton JP, Mahoudeau JA, Bouchard P, Thieblot P, Hautecouverture M, Simon D, et al: Treatment of Cushing's disease by O, p'DDD. Survey of 62 cases. N Engl J Med 300:459-464, 1979

44. Mercado-Asis LB, Yasuda K, Murayama M, Mune T, Morita H, Miura K: Beneficial effects of high daily dose bromocriptine treatment in Cushing's disease. Endocrinol Jpn 39:385-395, 1992

45. Miller JW, Crapo L: The medical treatment of Cushing's syndrome. Endocr Rev 14:443-458, 1993

46. Minniti G, Osti M, Jaffrain-Rea ML, Esposito V, Cantore G, Maurizi Enrici R: Long-term follow-up results of postoperative radiation therapy for Cushing's disease. J Neurooncol 84:79-84, 2007

47. Nakane T, Kuwayama A, Watanabe M, Takahashi T, Kato T, Ichihara K, et al: Long term results of transsphenoidal adenomectomy in patients with Cushing's disease. Neurosurgery 21:218-222, 1987

48. Nelson DH, Meakin JW, Dealy JB Jr, Matson DD, Emerson K Jr, Thorn GW: ACTH-producing tumor of the pituitary gland. $\mathbf{N}$ Engl J Med 259:161-164, 1958

49. Nelson DH, Meakin JW, Thorn GW: ACTH-producing pituitary tumors following adrenalectomy for Cushing's syndrome. Ann Intern Med 52:560-569, 1960

50. Nieman LK: Medical therapy of Cushing's disease. Pituitary 5: 77-82, 2002
51. Oldfield EH, Doppman JL, Nieman LK, Chrousos GP, Miller DL, Katz DA, et al: Petrosal sinus sampling with and without corticotropin-releasing hormone for the differential diagnosis of Cushing's syndrome. N Engl J Med 325:897-905, 1991

52. Ram Z, Nieman LK, Cutler GB Jr, Chrousos GP, Doppman JL, Oldfield EH: Early repeat surgery for persistent Cushing's disease. J Neurosurg 80:37-45, 1994

53. Schulte HM, Benker G, Reinwein D, Sippell WG, Allolio B: Infusion of low dose etomidate: correction of hypercortisolemia in patients with Cushing's syndrome and dose-response relationship in normal subjects. J Clin Endocrinol Metab 70:1426-1430, 1990

54. Sheehan JM, Vance ML, Sheehan JP, Ellegala DB, Laws ER Jr: Radiosurgery for Cushing's disease after failed transsphenoidal surgery. J Neurosurg 93:738-742, 2000

55. Sheehan JP, Niranjan A, Sheehan JM, Jane JA Jr, Laws ER, Kondziolka D, et al: Stereotactic radiosurgery for pituitary adenomas: an intermediate review of its safety, efficacy, and role in the neurosurgical treatment armamentarium. J Neurosurg 102: 678-691, 2005

56. Simmons NE, Laws ER Jr: Glioma occurrence after sellar irradiation: case report and review. Neurosurgery 42:172-178, 1998

57. Sonino N, Boscaro M, Paoletta A, Mantero F, Ziliotto D: Ketoconazole treatment in Cushing's syndrome: experience in 34 patients. Clin Endocrinol (Oxf) 35:347-352, 1991

58. Sonino N, Zielezny M, Fava GA, Fallo F, Boscaro M: Risk factors and long-term outcome in pituitary-dependent Cushing's disease. J Clin Endocrinol Metab 81:2647-2652, 1996

59. Stalla GK, Brockmeier SJ, Renner U, Newton C, Buchfelder M, Stalla J, et al: Octreotide exerts different effects in vivo and in vitro in Cushing's disease. Eur J Endocrinol 130:125-131, 1994

60. Thomas CG Jr, Smith AT, Benson M, Griffith J: Nelson's syndrome after Cushing's disease in childhood: a continuing problem. Surgery 96:1067-1077, 1984

61. Thompson SK, Hayman AV, Ludlam WH, Deveney CW, Loriaux DL, Sheppard BC: Improved quality of life after bilateral laparoscopic adrenalectomy for Cushing's disease: a 10-year experience. Ann Surg 245:790-794, 2007

62. Utz AL, Swearingen B, Biller BM: Pituitary surgery and postoperative management in Cushing's disease. Endocrinol Metab Clin North Am 34:459-478, 2005

63. Vella A, Thompson GB, Grant CS, van Heerden JA, Farley DR, Young WF Jr: Laparoscopic adrenalectomy for adrenocorticotropin-dependent Cushing's syndrome. J Clin Endocrinol Metab 86:1596-1599, 2001

64. Verhelst JA, Trainer PJ, Howlett TA, Perry L, Rees LH, Grossman $\mathrm{AB}$, et al: Short and long-term responses to metyrapone in the medical management of 91 patients with Cushing's syndrome. Clin Endocrinol (Oxf) 35:169-178, 1991

65. Vignati F, Loli P: Additive effect of ketoconazole and octreotide in the treatment of severe adrenocorticotropin-dependent hypercortisolism. J Clin Endocrinol Metab 81:2885-2890, 1996

66. Whitehead HM, Beacom R, Sheridan B, Atkinson AB: The effect of cyproheptadine and/or bromocriptine on plasma ACTH levels in patients cured of Cushing's disease by bilateral adrenalectomy. Clin Endocrinol (Oxf) 32:193-201, 1990

67. Zierhut D, Flentje M, Adolph J, Erdmann J, Raue F, Wannenmacher M: External radiotherapy of pituitary adenomas. Int J Radiat Oncol Biol Phys 33:307-314, 1995

Manuscript submitted June 21, 2007.

Accepted August 15, 2007.

Address correspondence to: James K. Liu, M.D., Division of Neurosurgery, Evanston Northwestern Healthcare, 2650 Ridge Avenue, Evanston, Illinois 60201. email: jliu@enh.org. 